\title{
O FIM DA REPÚBLICA BRASILEIRA E A URGÊNCIA DA EDUCAÇÃO PARA ALÉM DO CAPITAL
}

\author{
THE END OF THE BRAZILIAN REPUBLIC AND URGENCY OF EDUCATION BEYOND \\ CAPITAL
}

\section{EL FIN DE LA REPÚBLICA BRASILEÑA Y LA URGENCIA DE LA EDUCACIÓN ALTAS DEL CAPITAL}

DOI: http://dx.doi.org/10.9771/gmed.v11i1.32270

\author{
Henrique Tahan Novaes
}

Resumo: Este artigo aborda o fim da república brasileira para depois caracterizar brevemente a educação para além do capital e sua urgência no atual contexto brasileiro. Analisa também as lutas recentes dos movimentos sociais e sua potencialidade anticapital. Depois disso esboçamos a necessidade de uma teoria da transição ao socialismo adequada à nova fase do capitalismo no país.

Palavras-chave: Fim da República, Educação, Educação para além do capital

Abstract: This article approaches the end of the Brazilian republic and then briefly characterizes education beyond capital and its urgency in the current Brazilian context. It also analyzes the recent struggles of social movements and their anti-capital potentiality. After that we outline the need for a theory of transition to socialism appropriate to the new phase of capitalism.

Keywords: End of the Brazilian Republic, Education, Education beyond capital

Resumen: Este artículo aborda el fin de la república brasileña, caracteriza brevemente la educación más allá del capital y su urgencia en el actual contexto brasileño. También analiza las luchas recientes de los movimientos sociales y su potencial anticapital. Después de eso esbozamos la necesidad de una teoría de la transición al socialismo adecuada a la nueva fase del capitalismo.

Palabras clave: Fin de la República, Educación, Educación más allá del capital

\section{Introdução}

O Brasil vive um dos momentos mais difíceis da sua história. Como nos lembra Florestan Fernandes, o golpe fulminante de 1964, que completou 55 anos, se transfigurou nos anos 1980 em "institucionalização da ditadura”, pois houve uma transição lenta, gradual, segura, sem rupturas e acerto de contas com este período histórico.

Fernando Collor de Melo e sua ira farsesca venceram a eleição de 1989, depois de uma grande manipulação da TV Globo no $2^{\circ}$ turno. Fernando Henrique Cardoso aprofundou nosso neoliberalismo, com sua reforma do Estado e um grande ciclo de privatizações, aprimorando a ditadura do capital financeiro.

Depois de um curto período de ascensão do lulismo, dentro de uma estratégia de conciliação de classes e algumas concessões à classe trabalhadora (política de melhoria do salário mínimo, geração de emprego, cotas, direito das empregadas domésticas, etc.) tivemos um golpe de novo tipo em 2016, e em 
2018 a prisão política de Lula, que abriu espaço para eleição de um novo Collor, com suas soluções meteóricas de inspiração na ultradireita supostamente para "corrigir” os males o país.

As classes proprietárias declaram guerra aos trabalhadores. No caso brasileiro, interromperam as parcas vitórias da "Nova República", deram um golpe e enterraram a possibilidade de conciliar as classes sociais, ao ejetar o lulismo do poder. Elas estão promovendo a destruição das parcas conquistas da "Nova República" num ritmo mais acelerado.

Dias atrás o capitão reformado, atualmente na presidência da república, esteve nos EUA para anexar o Brasil como novo protetorado do império estadounidense (MAZIN et. al., 2019).

Este artigo pretende abordar o fim da república brasileira para depois caracterizar brevemente a educação para além do capital e sua urgência. Analisa também as lutas recentes dos movimentos sociais e sua potencialidade anticapital. Depois disso esboçamos a necessidade de uma teoria da transição adequada à nova fase do capitalismo, desemprego e subemprego estruturais.

\section{A nova etapa da contrarrevolução mundial e o fim da república brasileira}

No ano de 1962, Nelson Werneck Sodré publicou o livro “Quem é o povo no Brasil?”. Ele fez parte dos Cadernos do Povo Brasileiro, uma das melhores iniciativas dos anos 1960, que juntou Enio Silveira (Editora Civilização Brasileira) com a União Nacional dos Estudantes. Neste projeto foram feitos inúmeros livros com linguagem simples para problematização das principais questões que assolavam a nação. Obviamente, com o golpe de 1964 estes livros desapareceram das livrarias e das bancas.

55 anos atrás houve um golpe no Brasil e uma ditadura empresarial-militar de longa duração, com impacto profundo na nossa sociedade. Numa das passagens do livro de Sodré, que foi escrito antes do golpe de 1964, ele observa o receio das classes proprietárias brasileiras em manter a democracia naquele momento histórico. A passagem é longa, mas extremamente atual, merecendo ser citada:

O avultamento do problema democrático deriva de que a manutenção das liberdades democráticas permite o esclarecimento político, e o esclarecimento político permite a tomada de consciência pelo povo, e a tomada de consciência pelo povo permite a execução das tarefas progressistas que a fase histórica exige. Manter as liberdades democráticas, significa, pois, inevitavelmente, ter de enfrentar aquelas tarefas e resolvêlas, segundo a correlação de forças, quando as forças populares são muito mais poderosas do que as que estão interessadas na manutenção de uma estrutura condenada. Para mantê-la, entretanto, torna-se indispensável suprimir as liberdades democráticas.

O clima democrático asfixia progressivamente as forças reacionárias, que se incompatibilizaram definitivamente com ele, pedem, imploram um governo de exceção, um golpe salvador, uma poderosa tranca na porta a impedir a entrada do progresso. Tentam, com a frequência determinada pelas circunstâncias, a sinistra empresa, perdem sucessivamente todas as oportunidades, sendo levadas ao desespero. Mas procuram recuar em ordem, sempre, sacrificando alguns quadros de mais evidência, substituindoos, recondicionando-os, e seguem outro caminho, o de apresentar uma fachada democrática que esconda o fundo antidemocrático. Buscam, por todos os meios, organizar uma democracia formal em que seja estigmatizado como subversivo tudo o que fere o poder exercido pelos latifundiários e pela alta burguesia em ligação com o imperialismo, em que seja punível qualquer pensamento contra o atraso e a violência de classe. Essa ânsia exasperada em deter a marcha inevitável da história, em sustar o processo político, ameaça o País com a guerra civil, pois as forças antinacionais não recuarão ante ato algum que lhes prolongue o domínio. Assim como no campo internacional o imperialismo preferiria con-flagrar o mundo, com a guerra atômica, a 
ceder as suas posições, no campo nacional aquelas forças preferem conflagrar o País a ver derrotados os seus interesses. Poderão chegar a isso, ou não, entretanto, na conformidade com a correlação de forças sociais (SODRÉ, 2019, p. 61).

Ao que tudo indica, o golpe era para ser dado em 1954-55, mas Getúlio Vargas preferiu sair da vida pra entrar na história. Renunciou a sua vida, e adiou o golpe em 10 anos.

As forças democráticas daquele momento não foram suficientes para frear a marcha da contrarrevolução, materializada em 1964. Passados 52 anos do golpe de 1964, tivemos em 2016 um golpe de novo tipo, muito mais complexo de se perceber. E muito antes de 2016, as classes proprietárias, através de seus representantes no parlamento, bloquearam as "Diretas Já" e bloquearam a eleição de Lula, através de uma grande manipulação do $2^{\circ}$ turno na eleição de 1989.

Em 2014, nas condições normais de temperatura e pressão, tudo levava a crer que Aécio Neves iria ganhar as eleições. Depois de enorme campanha contra o lulismo, finalmente os tucanos voltariam ao poder. Mas pelos acasos da história Aécio perdeu as eleições por uma margem relativamente pequena. Ali a trama para retirar o lulismo do poder se aprofunda, culminando numa fatídica reunião do congresso que, em "nome de deus", em "nome da família", em nome de tantas coisas ejetou Dilma da presidência.

Não bastasse a retirada ilegítima de Dilma, houve em 2018 a prisão política de Lula. Aqui se repete algo que é regular na história do Brasil: é preciso "jogar para fora do ringue” todos os adversários. Depois de jogá-los para fora do ringue, são convocadas eleições "democráticas", para dar um ar de normalidade às instituições brasileiras.

O lulismo, que representa uma espécie de projeto "social-liberal", que obviamente não coloca em questão o capitalismo, mas concede alguns poucos direitos a uma parcela dos trabalhadores, é considerado pelas classes proprietárias uma "ameaça à ordem". Disso resulta nos dias de hoje que qualquer um pode tentar sua candidatura na nossa "democracia", desde que os candidatos defendam uma única e exclusiva proposta: o ultraliberalismo.

Nos dias de hoje, há uma espécie de "Triste fim da República brasileira". Obviamente aqui estou fazendo um paralelo com o livro "Triste fim de Policarpo Quaresma", o nosso maior nacionalista, que é preso e fuzilado por traição à nação. No livro, Lima Barreto nos mostra que a nossa república nasceu de um golpe e que os direitos republicanos tiveram pouca força no início da república: a) a escola que era para ser de massas não foi, b) a reforma agrária não foi realizada, c) os direitos para os ex-escravos não vieram, d) a construção da nação ficou para um outro momento.

É com Vargas que a construção da nossa república ganha um novo impulso: industrialização do país, expansão da escola pública e universidade pública, do funcionalismo público, criação das políticas habitacionais e principalmente a Consolidação das Leis do Trabalho. Mas no nosso triste fim, este projeto “morre" em 1954 e é duramente golpeado em 1964. De lá pra cá, estamos vivendo ondas sucessivas de destruição do pouco que restava.

Ao que tudo indica, a república brasileira acabou em 2016. Sindicatos estão sendo destruídos, partidos de esquerda destruídos, o SUS está sendo golpeado, a previdência pública também. As 
universidades públicas, com ampla hegemonia da direita, passam a ser atacadas por serem espaços de "comunistas".

Acima de tudo, a ampla reforma trabalhista do Sr. Temer, o golpista de plantão, enterra a CLT e a PEC do fim do mundo, jogando a última pá de cal na finada república brasileira.

No plano mundial estamos vendo as cenas de uma nova etapa da contrarrevolução mundial, iniciada nos anos 1970. Destruição parcial ou completa do Estado de Bem Estar Social na Europa, guerras de baixa intensidade, reestruturação produtiva, crescimento exponencial do capital fictício, crescimento do desemprego e subemprego estruturais e ascensão de ideias e governos neofascistas. Do nosso ponto de vista, o capitalismo não tem mais nada a oferecer à humanidade, o que coloca na ordem do dia a educação para além do capital, tema da nossa próxima seção.

\section{A urgência da educação para além do capital}

É neste período que intensificamos nossas atividades políticas. Imersos nas lutas do nosso tempo histórico, em alguma medida temos contribuído para a experimentação da educação para além do capital em nossos espaços institucionais e fora deles. Nossos grupos de pesquisa têm feito inúmeros cursos com os movimentos sociais em geral, e em especial com o MST, que exercitam em alguma medida os princípios da educação para além do capital: a) um corpo de professores de esquerda, especialmente vindos do materialismo, que socializam conteúdos críticos e lutam pela construção de uma sociedade para além do capital no plano mundial; b) o aprendizado junto aos alunos trabalhadores, num processo dialógico de troca de conhecimentos, c) a experimentação da autogestão nos cursos, com graus distintos de radicalidade de acordo com as possibilidades e especificidades dos cursos, d) a construção de uma teoria da transição comunista e a tentativa de organização da classe trabalhadora para um projeto internacionalista e revolucionário, tendo em vista a emancipação humana (LIMA FILHO, 2019).

Poderíamos destacar aqui os seguintes cursos: a) Técnico em Agroecologia, b) Curso Técnico em agropecuária integrado ao ensino médio, com ênfase em agroecologia e agrofloresta, c) Mini Curso Itinerante Questão Agrária, Cooperação em Agroecologia (6 Edições), d) Curso de Aperfeiçoamento Itinerante Movimentos Sociais e Crises Contemporâneas (10 Edições).

O Curso Técnico em agropecuária integrado ao ensino médio, com ênfase em agroecologia e agrofloresta, começou em março de 2019. O curso é fruto de uma demanda do MST e demais movimentos sociais do campo tendo em vista a escolarização e qualificação da população que vive do campo.

Trata-se de um curso de 3 anos, dividido em Tempo Escola e Tempo Comunidade (Pedagogia da Alternância). Realizado na Escola de Educação Popular Rosa Luxemburgo, da regional do MST de Iaras, pretende teorizar e praticar a agroecologia, dentro de uma perspectiva que supere o horizonte do "consumo responsável", do "desenvolvimento" sustentável, e todas as ideologias baseadas na produção destrutiva, intrínseca ao sociometabolismo do capital. 
Por um lado, o objetivo é estudar a questão agrária, criticar e denunciar cientificamente a "revolução verde", e por outro, estudar e experimentar a agroecologia, tendo em vista a luta pela Reforma Agrária Popular e Agroecológica (RAPA)

Somos partidários do estudo da história na perspectiva materialista e dialética. Temos partido, o partido da ciência e somos comprometidos com as lutas emancipatórias da classe trabalhadora. Num contexto onde a ciência é colocada a prova, num contexto onde os professores que defendem pautas mínimas são colocadas na fogueira da nova inquisição, estamos tentando resistir a esta avalanche de irracionalismo.

Nos colocamos contra o desmonte da nação e nos comprometemos a publicar livros de qualidade acessíveis ao público brasileiro, que tem "sede" de conhecimento crítico.

Para este curso, estamos montando uma série de Livros de Bolso, de caráter introdutório. Já publicamos “Sobre o óbvio” de Darcy Ribeiro, “Quem é o povo no Brasil?”, de Nelson Werneck Sodré. O texto "A conspiração contra a escola pública" de Florestan Fernandes está em fase de acabamento. Pretendemos ainda publicar livros sobre e de Caio Prado Júnior, Celso Furtado, Heleieth Saffioti, dentre outras e outros pesquisadores brasileiros mais jovens.

Combatendo nas trevas, começamos em 2014 o Curso Técnico em Agroecologia, também em parceria com o MST e o Centro Paula Souza. Dele derivaram o Mini Curso Itinerante Questão Agrária, Cooperação e Agroecologia e o Curso Técnico em Agropecuária integrado ao Ensino Médio, descrito acima. O curso Técnico em Agroecologia foi realizado na Escola Rosa Luxemburgo, tendo como público jovens de movimentos sociais do campo que já tinham ensino médio.

Também em 2014 começamos o Curso Itinerante Movimentos Sociais e Crises Contemporâneas. Já tivemos 9 edições e o curso caminha pra $10^{a}$ Edição na cidade de Limeira-SP. Pelo curso já passaram cerca de 1.200 pessoas (entrada de 120 por turma), com uma média de 50 alunos concluintes por turma. Deste curso derivou o mini curso Marx e Revolução na Periferia, em parceria com a Apeoesp Zona Leste (SP), Frente Brasil Popular e Frente Povo Sem Medo. Cabe salientar que o mesmo será retomado em 2019.

Com o objetivo de retornar a Marx, temos promovido inúmeros cursos, minicursos, palestras, seminários, realização de pesquisas, atividades de extensão e outras atividades desde 1999.

$\mathrm{Na}$ América Latina, a Escola Nacional Florestan Fernandes (ENFF), a Escola José Carlos Mariátegui (Argentina), o Núcleo de Educação Popular 13 de Maio, algumas escolas de centrais sindicais, partidos políticos, outras escolas do MST, dentre inúmeras outras experiências que não poderemos citar neste espaço, estão oferecendo cursos com conteúdos críticos e formas pedagógicas alternativas.

Estas lutas educacionais recuperam os projetos de Universidade Popular advogados por José Carlos Mariátegui nos anos 1910-20, do Instituto Superior de Estudos Brasileiros (ISEB) nos anos 1960, de Educação Popular nos anos 1950-60, dentre outros. Acreditamos que estes cursos e nossos cursos certamente terão uma importância significativa no século XXI.

Nossos cursos são voltados para membros de movimentos sociais: sindicatos de esquerda, partidos de esquerda, sem terra, sem teto, feministas, membros do movimento negro, professores 
universitários, docentes das escolas públicas, educadores populares, ambientalistas, lideranças populares, etc.

Nos dias de aula, os alunos se auto-organizam para preparar os lanchinhos, limpar a sala de aula, escolher duas aulas livres, organizar a caixinha, apresentar os projetos de pesquisa e artigos científicos, gravar as aulas, fazer a memória da aula, controlar o tempo dos professores, etc.

No Módulo I, denominado "Marx e o materialismo crítico" debatemos a obra de Marx e de alguns clássicos do materialismo crítico, como por exemplo, Vladimir Lenin, Rosa Luxemburgo, Antonio Gramsci, Gyorgy Lukács, José Carlos Mariátegui, Che Guevara e István Mészáros. Também debatemos alguns temas históricos, como as revoluções burguesas radicais e conservadores, bem como as particularidades da América Latina.

O Módulo II, denominado "Movimentos Sociais e Crises Contemporâneas à luz dos clássicos do materialismo crítico", aborda algumas crises contemporâneas: a) crise do desemprego estrutural e subemprego estrutural; b) a produção destrutiva, a ofensiva do agronegócio e a crise ambiental; c) a "crise" do Estado, a mercantilização da saúde e da educação. Da mesma forma, abordamos alguns movimentos sociais e o potencial das lutas anticapital que estão surgindo na América Latina, das quais poderíamos destacar a luta pela terra, por teto, pela cidade como valor de uso, pelo trabalho associado, contra os agrotóxicos e pela agroecologia, as lutas dos catadores de materiais recicláveis, as lutas por igualdade de gênero, a relação entre classe, etnia e gênero, as lutas indígenas diante do avanço da acumulação por espoliação, dentre outras. Receberam igual importância a nova geopolítica mundial, o tratamento do golpe de 2016, o avanço da direita na América Latina e a Comissão Nacional da Verdade.

Este curso faz parte do projeto "Escola Marx". Nele pretendemos voltar a estudar a obra de Karl Marx e contribuir para a revolução latino-americana, realizar cursos em todas as partes da América Latina sobre Marx e o materialismo crítico.

Para este curso foram preparados 3 livros, com textos feitos especialmente pelos professores do curso para os alunos do curso. De acordo com Candido Vieitez (2017) trata-se de uma importante iniciativa no campo do que estamos chamando educação para além do capital. Pedimos desculpas ao leitor, mas o prefácio do Professor Vieitez ao volume 2 do livro do curso merece ser citado, ao menos uma boa parte dele:

Os textos que compõem esta coletânea são valiosos por si próprios. No entanto, o seu significado mais importante, em nosso entender, encontra-se no fato de que são a expressão literária da atividade pedagógica desenvolvida pelos seus autores no curso Movimentos Sociais e Crises Contemporâneas à Luz dos clássicos do Materialismo Crítico.

Conforme consta na apresentação deste livro, esse curso, organizado por membros do IBEC e do GPOD, foi idealizado tendo em vista sobretudo os militantes dos movimentos sociais, ou, melhor, dos movimentos sociais lato censo considerados, o que abrange sindicalistas, integrantes dos partidos políticos, membros de movimentos do campo dentre outros.

A criação e execução de um curso de aperfeiçoamento, mesmo que com esse propósito pode aparecer como acontecimento prosaico. Mas, não é o caso, uma vez que a sua realização tem implicações pedagógicas e políticas significativas.

O curso foi aprovado pela Universidade, o que lhe proporciona certificação e certo apoio, fato que tampouco é trivial, posto que a universidade, mesmo a estatal, ao contrário do auto propalado, não é o lugar de cultivo da cultura universal. Com efeito, a universidade encontra-se direcionada para atender os requisitos de replicação do capital, 
o que pouco tem a ver com a organização de cursos para os militantes dos movimentos sociais. Em consequência, a organização de um curso desse tipo é virtualmente conflitiva e por vezes, inviável. E, em todo caso, depende da presença de uma vontade política determinada, que seja capaz de aproveitar as contradições e fissuras presentes em qualquer organização escolar. De qualquer modo, da empreitada resulta também um exemplo que poderá ser anotado por aqueles que, insertos no ensino universitário, se importam com a classe trabalhadora, com sua própria educação e organização.

Embora tendo emergido na universidade, o curso não se cinge ao seu intramuros. Ainda que de alcance todavia restrito, o mesmo vem sendo ministrado em vários pontos do Estado, como bem observa a apresentação. Ressaltemos também que ademais do evidente empenho em alargar o alcance dessa atividade, os organizadores certamente especulam sobre as potencialidades de seu desenvolvimento junto ao movimento operário e popular (MOP), sob esse ou outro formato.

Um dos aspectos mais significativos do Curso é que retoma uma prática que andou um tanto esquecida, qual seja, a de que os marxistas com formação teórica contribuam com ações concretas para a elevação cultural e política dos trabalhadores mediante a prática reiterada de estudo. O Partido Operário Socialdemocrata Russo (bolchevique), antes de empolgar o poder ficou conhecido como o "partido dos livreiros" em virtude dessa atividade. E Lênin, segundo Krupskaya (1986), em seu tempo de atuação nos círculos ou grupos de estudo, tinha como uma de suas tarefas discutir pedagogicamente $O$ Capital de Marx com os operários.

Essa prática de Lênin, pela qual um pensador se coloca numa situação de interação direta com os trabalhadores, seus movimentos e suas organizações, perfazendo uma espécie de "fusão" entre a atividade intelectual e a militância política, faz parte da tradição marxista. De fato, essa história começou com Marx e Engels. Primeiro porque o encontro deles com o MOP foi uma das determinantes no processo que os levou à conceptualização do materialismo histórico (GORAN, 1980). E depois, porque na condição de militantes/pesquisadores, vieram a exercer várias funções no movimento operário.

Essa prática dos fundadores se estendeu no tempo, e pelo que nos consta, as principais contribuições à teoria marxista foram ainda realizadas por intelectuais-militantes. Depois da Segunda Guerra, em correspondência talvez com certa fragilização do marxismo, principalmente o marxismo enquanto prática, destacaram-se os denominados marxistas acadêmicos, aparentemente mais centrados na vida profissional universitária. Seja como for, essa interação profunda ou orgânica entre o estudioso marxista e o MOP se afigura como uma tendência do método marxista, observadas, naturalmente, as intermitências ou variações postas pelo curso da sociedade.

Convenhamos, no entanto, que essa atividade pedagógica significa mais que o usual na pedagogia bancária burguesa, pois, se é fato que os militantes podem aprender com os professores, estes, dada a natureza intrínseca do marxismo, também podem aprender com os alunos, antes de tudo com os que são integrantes de movimentos ou organizações do MOP, as quais, de modo incipiente ou já estruturado, têm suas próprias análises e formulações sobre a realidade social (VIEITEZ, 2017, p. 14).

Evidentemente que esses cursos têm inúmeras limitações, principalmente no que se refere aos aspectos quantitativos. Estamos diante de uma nova fase da ofensiva do capital, que está produzindo um processo de destruição das pequenas conquistas da "nova república". Se isso é verdade, uma ofensiva da educação para além do capital deverá se dar através da multiplicação exponencial (células) de cursos autônomos, fora do controle do Estado, e ao mesmo tempo "contaminar" a escola estatal, colocando na agenda dos trabalhadores docentes da escola estatal a urgência de uma radical transformação do que se ensina, como se ensina-aprende, como se avalia e quais os fins da educação na sociedade de transição.

Como e por que caminhar para além do capital no século XXI? 
No Brasil, os movimentos sociais dos anos 1930-60 foram destroçados pela ditadura de 19641985. Na segunda metade dos anos 1970, depois de um longo e traumático período, surgiram inúmeras lutas puxadas pelos trabalhadores.

Eclodiram em todos os cantos do país lutas contra a fome, por habitação, por emprego, por melhores salários, por melhores condições de trabalho e salários para o funcionalismo público; lutas dos bancários, lutas por terra e por teto, por creches, por saneamento básico; lutas por educação e pela democratização da escola pública, lutas dos atingidos por barragens etc., evidentemente combinadas com as lutas pelo fim da ditadura².

No fim das contas, o capital saiu vitorioso com sua "transição gradual, lenta e segura". Não conseguimos as Diretas Já. O capital esteve no controle dessa transição, a ponto de Florestan Fernandes (1986) se perguntar se estávamos mesmo entrando na fase da "Nova República"3. Saímos da ditadura empresarial militar e entramos na ditadura do capital financeiro. Essa fase da nossa convencionou chamar de "redemocratização".

Nos anos 2000 a luta pela terra ganha novos ares. Foram intensas as lutas contra os agrotóxicos, transgênicos e adubos sintéticos, mais precisamente, contra o pacote da "revolução verde" e a materialização da agroecologia. Para nós, o Movimento dos Trabalhadores Rurais Sem Terra (MST) é um dos movimentos sociais que está promovendo a denúncia do pacote da "revolução verde", e a implantação de sistemas agroecológicos.

Já afirmamos em outros textos que a agroecologia não irá avançar sem a conquista da terra. Sem uma "revolução agrária", infelizmente, não há agroecologia. Sem a superação do trabalho exploradoalienado, não há agroecologia. Sem o avanço do feminismo, não há agroecologia. Seguindo nessa linha, sem uma completa desmercantilização da sociedade e sem soberania alimentar, não há agroecologia. O que é possível materializar no atual contexto de ofensiva do capital são embriões de produção agroecológica, mas obviamente muito distantes de um novo modo de produção, autogerido e agroecológico.

Movimentos sociais como o Movimento dos Trabalhadores Rurais Sem Terra (MST) têm defendido uma "reforma agrária popular". Tudo leva a crer que as classes proprietárias brasileiras não aceitarão a reforma agrária, muito menos uma reforma agrária de caráter popular. Como um grande produtor de riqueza e de miséria, o Brasil tornou-se um dos maiores celeiros da humanidade, mas também um dos maiores celeiros de miséria. O Brasil produz milho para porcos e frangos, mas não tem milho para alimentar os filhos da classe trabalhadora ${ }^{4}$.

Segundo David Harvey (2004) e Walter Gonçalves et al. (2016), o Brasil é um dos palcos centrais da "acumulação por espoliação". Roubo de terras públicas, cercamento ilegal de terras, roubo de terras de posseiros, pequenos produtores, faxinalenses etc. tornaram-se mais comuns do que imaginamos ${ }^{5}$.

Nesse sentido, a soberania alimentar, isto é, a luta contra a produção e a exportação de commodities ganha um papel primordial à medida que o que está em questão é a alimentação adequada dos seres humanos, e não a "alimentação dos lucros do capital". Assim como o campo é um palco de lutas, ao que tudo indica, nesta nova fase do capitalismo surgirão inúmeras lutas contra o fechamento de escolas, lutas por teto, por transporte público barato e de qualidade, por acesso à universidade pública e por saúde pública. 
Como vimos na seção anterior, as parcas conquistas republicanas duramente arrancadas pelos trabalhadores estão sendo destruídas numa espécie de "desproclamação da República".

Se nos anos 1990 o MST se destaca na luta pela terra, nos anos 2000 é preciso destacar a luta do Movimento Sem Teto, com suas inúmeras marchas por moradia e contra a cidade como valor de troca: transporte caro, onde a classe trabalhadora passa em média 3 horas por dia exprimida em ônibus antigos e metrôs, "unidas na marra" em locais quentes e apertados. Denúncias e ações contra a especulação imobiliária, críticas às praças públicas de baixa qualidade, creches terceirizadas ou inexistência das mesmas, fechamento de classes noturnas, falta de saneamento básico, etc. também aparecem no discurso das lideranças.

Com o avanço do Plano de Aceleração do Crescimento (PAC) e das Grandes Obras dos anos 2000 e 2010 como rodovias, portos, aeroportos, estádios da Copa surgem novas lutas por melhores condições de trabalho e alojamento nestas obras, ações dos atingidos por barragens contra usinas hidrelétricas, e manifestações contra a implantação destas grandes obras.

Por sua vez, as classes médias e parcelas da classe trabalhadora saíram às ruas, em grandes manifestações puxadas por movimentos como "Vem pra rua", "Movimento Brasil livre", "Revoltados online", aprofundando o clima de ódio de classes no seio da sociedade brasileira. Bandeiras extremamente conservadoras como o combate a corrupção, a prisão de Lula, a negação das cotas, direitos das empregadas domésticas, etc. deram vazão aos pedidos de impeachment (que na verdade é um golpe) que levou ao poder Michel Temer, a prisão política de Lula e a eleição de um capitão reformado expulso dos quartéis.

Então, diante deste contexto de ofensiva do capital, de destruição da república, qual é então o desafio para os movimentos sociais anticapital?

O primeiro de todos - no caso brasileiro - é o de reestabelecer a nossa democracia e de acabar que este golpe institucional o mais rápido possível.

Além disso, fazer avançar as lutas anticapital, como estamos defendendo neste capítulo. Aparentemente lutar contra o fechamento de escolas, contra a destruição da saúde pública, lutar por terra, por moradia e por melhores salários/direitos trabalhistas são lutas reformistas. Mas, no contexto de ofensiva do capital, elas ganham um caráter radical, por mais difícil que isso possa parecer.

No entanto, acreditamos que nossas lutas precisarão avançar rumo a bandeiras anticapital mais "precisas" e integradas: a autogestão, a cooperação, a desmercantilização, a terra de trabalho (e não a terra de negócios), a soberania alimentar, a utilização adequada dos recursos dos ecossistemas, a igualdade substantiva e a educação para além do capital.

Lutas pelo definhamento do Estado capitalista e de sua burocracia, pela propriedade comunal e pela unificação internacional das lutas anticapital são bons exemplos do que estamos “propondo". Sem elas, dificilmente caminharemos rumo a uma revolução na América Latina: as corporações transnacionais continuarão mandando em nossas vidas, e as elites regionais se deleitando com as nossas lutas pontuais, desconectadas e efêmeras.

Em outras palavras, na falta dessas bandeiras, as classes proprietárias poderão até ceder aqui ou ali, mas a essência do sociometabolismo do capital estará preservada. $\mathrm{Na}$ falta dessas bandeiras, a luta pela 
terra irá se tornar agricultura familiar, a luta por teto irá se tornar no máximo um puxadinho de Minha Casa Minha Vida, sob o comando das corporações. A luta pela agroecologia permanecerá no terreno do “consumo responsável” e assim por diante.

Nossas lutas também não poderão ficar no terreno eleitoral. Como nos alerta Mészáros (2008, p. 18), as lutas do século XXI devem ter como base as lutas extraparlamentares:

(...) a força extraparlamentar original e potencialmente alternativa do trabalho transformou-se, na organização parlamentar, permanentemente desfavorecida. Embora esse curso de desenvolvimento pudesse ser explicado pelas fraquezas óbvias do trabalho organizado em seu início, argumentar e justificar desse modo o que havia realmente acontecido, nas atuais circunstâncias, é apenas mais um argumento a favor do beco sem saída da socialdemocracia parlamentar. Pois a alternativa radical de fortalecimento da classe trabalhadora para se organizar e se afirmar fora do Parlamento - por oposição à estratégia derrotista seguida ao longo de muitas décadas até a perda completa de direitos da classe trabalhadora em nome do "ganhar força" - não pode ser abandonada tão facilmente, como se uma alternativa de fato radical fosse a priori uma impossibilidade.

Para nós, a luta no século XXI deve estar centrada nas ruas, no trabalho de base para a superação do trabalho emancipado, na música crítica, no cordel, na unidade dos movimentos sociais, nas festas populares etc. Sempre tendo em vista a superação do trabalho alienado e sua forma de política correspondente, igualmente alienada. Em outras palavras, a luta deve passar pelo parlamento, mas deve ser fundamentalmente extraparlamentar.

A história nos mostra também a necessidade de uma revolução. As lutas na América Latina não comportam o gradualismo e o reformismo típicos dos partidos de esquerda das últimas décadas. Não é possível unir-se, conciliar as classes, aliar-se ao capital. Vimos o desfecho do melhorismo no lulismo: com o aprofundamento da crise econômica, a aristocracia operária foi “ejetada” do governo, num perfeito golpe parlamentar-jurídico.

Evidentemente que uma revolução necessita de uma teoria revolucionária adequada para o século XXI e adequada para as especificidades da América Latina. Sendo assim, a conquista da terra na América Latina pelos camponeses, indígenas, quilombolas e trabalhadores rurais somente se dará dentro de um quadro revolucionário. $\mathrm{Na}$ falta dela, como vimos, a agenda agroecológica dos movimentos sociais irá avançar a passos lentos, muito provavelmente na forma de um ecocapitalismo tolerável pelas classes dominantes ou na forma de um agronegócio "verde".

O avanço da agroecologia dentro de uma estratégia ecocomunista e autogestionária depende da luta política, ou melhor, do avanço das lutas anticapital dos movimentos sociais e da formação da consciência revolucionária.

$\mathrm{Na}$ América Latina, o sujeito revolucionário é múltiplo e mais complexo do que o lema “operários e camponeses", vigente no século XX. A construção da unidade das lutas de indígenas, quilombolas, camponeses e camponesas, trabalhadores rurais, classe trabalhadora urbana assalariada, formal e informal, e da nova classe trabalhadora terceirizada não será nada fácil, mas é imprescindível.

Nós da esquerda, estávamos acostumados até os anos 1970 a impulsionar lutas pensando na classe trabalhadora assalariada taylorista-fordista. De lá pra cá, o capitalismo mudou. Ainda não há uma teoria da transição na América Latina pensada para essa nova configuração do capitalismo. 
Também é preciso destacar outra obviedade. Com a degradação dos serviços públicos nos últimos anos na América Latina, novos personagens entraram na cena das lutas urbanas: trabalhadores docentes do ensino médio, do ensino superior e fundamental reagiram a precarização do trabalho docente. Servidores da saúde, assistência social, entre inúmeros outros que passaram a entrar na lista dos lutadores do século XXI e, portanto, fazem parte da nova classe trabalhadora. São assalariados do Estado, ou como se dizia nos anos 1980, “o patrão é o Estado!", Estado a serviço das classes proprietárias, que não querem construir serviços públicos dignos, não quer remunerar decentemente o funcionalismo público e muito menos permitir que os mesmos tenham boas condições de trabalho e aposentadoria.

A ascensão do movimento indígena na Bolívia, no Equador e no México também não pode ser desprezada. No Brasil, o processo de avanço da nova fronteira agrícola pelo agronegócio está levando ao surgimento de novas lutas de índios, quilombolas, posseiros etc.?

Por último, mas não menos importante, é preciso ter em mente que a superação do sociometabolismo do capital depende de uma revolução sociopolítica, mas que a superação do capital enquanto relação social é um processo longo, que pode durar 500, 600 anos, ou até mais. Ao que tudo indica, a desmercantilização completa da sociedade, isto é, a superação da sociedade comandada pela mercadoria, pode ser iniciada por uma revolução, mas demandará um esforço organizado e consciente dos trabalhadores para retomar o comando do sociometabolismo, tendo em vista a produção de valores de uso pelos produtores livremente associados.

A conquista dos meios de produção tornou-se tarefa vital no século XXI. Mais do que isso, a conquista e o controle dos meios de produção pelos trabalhadores, tendo em vista a construção de uma sociedade governada por produtores livremente associados, totalmente desmercantilizada, tornou-se tarefa vital no século XXI.

Nas palavras de Mészáros (2002), é urgente a criação de uma nova forma de controle social, baseada no poder comunal, tendo como eixo a propriedade comunal. Se para ele a conquista dos meios de produção é algo imprescindível, a questão fundamental ainda é o controle do sociometabolismo, tendo em vista a emancipação da humanidade do jugo do capital.

\section{Referências}

DAVIS, Mike. Planeta favela. São Paulo: Boitempo, 2007.

DEO, Anderson. Autocracia burguesa e questão agrária no Brasil. In: PIRES, J. H. et. al. (orgs.) Questão agrária, cooperação e agroecologia. Uberlândia (MG): Navegando, 2017, volume vol. 3.

DEO, Anderson. Uma transição à long term: a institucionalização da autocracia burguesa no Brasil. In: Milton Pinheiro. (org.). Ditadura: o que resta da transição. São Paulo: Boitempo Editorial, 2014, v. 1, p. 303-330.

DUARTE, Rodrigo. Marx e a natureza em O capital. Rio de Janeiro: Loyola, 1986.

GONÇALVES, Walter Porto et. al. In: Conflitos no campo 2015. Goiânia: CPT, 2016. 
GUHUR, Dominique. Questão ambiental e agroecologia: notas para uma abordagem materialista dialética. In: NOVAES, H. T.; MAZIN, A. D.; SANTOS, L. Questão agrária, cooperação e agroecologia. São Paulo: Expressão Popular, 2015, vol I.

HARVEY, David. O novo imperialismo. São Paulo: Loyola, 2004.

KOVEL, Joel; LOWY, Michel. Manifesto ecossocialista internacional. Revista "Capitalism, Nature, Socialism A Journal of Socialist Ecology", 2003.

LENIN, Vladimir. Imperialismo: - fase superior do capitalismo. São Paulo: Centauro, 2003.

LIMA FILHO, Paulo A. Sobre as revoluções burguesas radicais. In: NOVAES, H. T.; DAL RI, N. (orgs.) Movimentos sociais e crises contemporâneas à luz dos clássicos do materialismo crítico. Uberlândia (MG): Navegando, 2017, volume vol. 2.

LIMA FILHO, Paulo Alves de. Pensando com Marx (I). Marília-São Paulo: Lutas anticapital-Aramarani, 2018.

LIMA, A. GUHUR, D. TONÁ, N.; NOMA, A. Reflexões sobre a educação profissional em agroecologia no MST: desafios dos cursos técnicos do Paraná. In: RODRIGUES, F. C.; NOVAES, H. T.; BATISTA, E. L. (orgs.) Movimentos sociais, trabalho associado e educacão para além do capital. São Paulo: Outras Expressões, 2012.

LOWY, Michel. Ecologia e socialismo. São Paulo: Cortez, 2003.

LOWY, Michel. Ecossocialismo e planejamento democrático. Crítica Marxista, n. 28, 2009, p. 35-50.

MACEDO, Rogério Fernandes. A destruição em massa: a tragédia da fome e da degradação dos hábitos alimentares. In: NOVAES, H. T.; SANTOS, J.; PIRES, J. H. (orgs.) Questão agrária, cooperação e agroecologia, vol. I. São Paulo: Outras Expressões, 2015.

MACHADO, FILHO, Luiz P.; MACHADO FILHO, Luiz P. A dialética da agroecologia: - contribuição para um mundo com alimentos sem veneno. São Paulo: Expressão Popular, 2013.

MARQUES, Luiz. Capitalismo e colapso ambiental. Campinas: Ed. Unicamp, 2015.

MÉSZÁROS, I. Atualidade histórica da ofensiva socialista:- uma alternativa radical ao sistema parlamentar. São Paulo: Boitempo Editorial, 2008.

MÉSZÁROS, István. O desafio e o fardo do tempo bistórico. São Paulo: Boitempo Editorial, 2007.

MÉSZÁROS, István. O poder da ideologia. São Paulo: Boitempo Editorial, 2004.

MÉSZÁROS, István. Para além do capital. São Paulo: Boitempo Editorial, 2002.

MINTO, Lalo W. Governo e educação novamente golpeados: consequências para o ensino superior e o trabalho docente. In: MACEDO, R. F.; NOVAES, H. T.; LIMA FILHO, P. A. (orgs). Movimentos sociais e crises contemporâneas. Marília (SP): Lutas Anticapital, 2018, volume vol. 3.

NETTO, José Paulo. Prefácio. In: ZIEGLER, Jean. Destruição em massa: - geopolítica da fome. São Paulo: Cortez, 2013.

NETTO, José Paulo. Uma face contemporânea da barbárie. Rio de Janeiro, 2008.

NOVAES, H. T.; PIRES, J.H. Corporações transnacionais, a agenda agroecológica do MST e as escolas de agroecologia. In: NOVAES, H.T.; MACEDO, R. F.; LIMA FILHO, P. A. (orgs) Movimentos sociais e crises contemporâneas. Uberlândia (MG): Navegando, 2017, vol. 2.

NOVAES, Henrique T.; SANTOS, Lais; PIRES, João; FUZER, Antônio. A economia política da "revolução verde", a agroecologia e as escolas de agroecologia do MST. In: NOVAES, H. T.; MAZIN, A. D.; SANTOS, L. Questão agrária, cooperação e agroecologia. São Paulo: Expressão Popular, 2015, vol I.

NOVAES, Henrique Tahan. Prefácio. In: Cidadania do capital? A estratégia da intervenção social das corporações empresariais. São Paulo: Sundermann, 2017. 
NOVAES, Henrique Tahan. Reatando um fio interrompido: - a relação universidade movimentos sociais na América Latina. São Paulo: Expressão Popular-Fapesp, 2012.

PETERSEN, Paulo. Apresentação - Um novo grito contra o silêncio. In: Dossiê Abrasco. São Paulo: Expressão Popular, 2013.CARNEIRO, Fernando Ferreira (org.) Dossiê Abrasco: um alerta sobre os impactos dos agrotóxicos na saúde. Rio de Janeiro: EPSJV; São Paulo: Expressão Popular, 2015, p.27-36.

PINASSI, Maria O; MAFORT, K. Os agrotóxicos e a reprodução do capital na perspectiva feminista da Via Campesina. In: RODRIGUES, F. C.; NOVAES, H. T.; BATISTA, E. (orgs.) Movimentos sociais, trabalho associado e educação para além do capital. São Paulo: Outras Expressões, 2012.

PINHEIRO MACHADO, Luiz C.; PINHEIRO MACHADO FILHO, L. C. A dialética da agroecologia. São Paulo: Expressão Popular, 2014.

PIRES, João Henrique Souza; NOVAES, Henrique Tahan. Estudo, trabalho e agroecologia: a proposta política pedagógica dos cursos de agroecologia do MST no Paraná. In: Germinal: marxismo e educação em debate, Salvador, v. 8, n. 2, p. 110-124, dez. 2016.

PISTRAK, Moisey M. Fundamentos da escola do trabalho. 4ª ed. São Paulo: Expressão Popular, 2005.

PLOEG, Jan. Camponeses e impérios alimentares: lutas por autonomia e sustentabilidade na era da globalização. Porto Alegre: UFRGS, 2008.

PRADO JR., Caio. A revolução brasileira. São Paulo: Brasiliense, 2002.

REGO, Thelmely Torres. Formação em agroecologia. Programa do Contestado da AS-PTA. 313f. Tese (Doutorado em Educação), UFSC, 2016.

RODRIGUES, Fabiana. MST: - formação política e reforma agrária nos anos de 1980. Tese de Doutorado, Campinas, Faculdade de Educação, 2013.

SACHS, Ignacy. Espaços, tempos e estratégias de desenvolvimento. São Paulo: Vértice, 1987.

SADER, Eder. Quando novos personagens entram em cena. Rio de Janeiro: Paz e Terra, 1988.

SAMPAIO JR., P. Notas críticas sobre a atualidade e os desafios da questão agrária. In: STEDILE, J. P. (org.) Debates sobre a situação e perspectivas da reforma agrária na década de 2000. São Paulo: Expressão Popular, 2013, p. 189-240.

SANTOS, L. Gestão democrática e participação na educação profissional agroecológica do MST (PR): limites e possibilidades de uma educação emancipatória. 150f. 2015. Dissertação (Mestrado em Educação), UNESP, 2015.

SEVÁ FILHO, A. Populações e territórios espoliados pela ampliação recente da infraestrutura industrial capitalista: focos de luta política e ideológica na América do Sul. Marília: Lutas anticapital, 2019.

SHULGIN, Viktor. N. Rumo ao politecnismo. 1 ed. São Paulo: Expressão Popular, 2013.

SILIPRANDI, Emma. Mulheres e agroecologia: a construção de novos sujeitos políticos na agricultura familiar. 2009. 292f. Tese (Doutorado) - Desenvolvimento Sustentável, UnB, 2009.

SODRÉ, Nelson Werneck. Quem é o povo no Brasil? Marília: Lutas anticapital, 2019.

TAIT, Marcia. Elas dizem não! Mulheres camponesas e resistência ao cultivo de transgênicos no Brasil e Argentina. 220f. 2014. Tese. (Doutorado em Política Científica e Tecnológica), Universidade Estadual de Campinas.

TORRES, Michelangelo. Cidadania do capital? A estratégia da intervenção social das corporações empresariais. São Paulo: Sundermann, 2017.

VIEITEZ, Candido. Prefácio. In: NOVAES, H. T.; DAL RI, N. (orgs.) Movimentos sociais e crises contemporâneas à luz dos clássicos do materialismo crítico. Uberlândia (MG): Navegando, 2017, volume vol. 2.

VILLAÇA, Flavio. O que todo cidadão precisa saber sobre habitação. São Paulo: Ed. Global, 1986. 
ZIEGLER, Jean. Destruição em massa: - geopolítica da fome. São Paulo: Cortez, 2013.

\section{Notas:}

${ }^{1}$ Possui graduação em Ciências Econômicas pela Unesp - Araraquara (2001) e mestrado (2005) e doutorado (2010) em Política Científica e Tecnológica pela Unicamp. No mestrado estudou o Processo de Adequação Sóciotécnica nas Fábricas Recuperadas brasileiras e argentinas, com financiamento da Fapesp. Sua dissertação resultou no Livro - O fetiche da tecnologia: a experiência das fábricas recuperadas - (Expressão Popular/Fapesp, 2007. E 2010, 2a Edição). No doutorado, também com bolsa Fapesp, estudou - a relação universidade-movimentos sociais na América Latina: habitação popular, agroecologia e fábricas recuperadas. Tem experiência na área autogestão, fábricas recuperadas, economia solidária, educação no trabalho associado, gestão educacional, políticas públicas, reforma do Estado, economia industrial, mundo do trabalho - desemprego e subemprego, política científica e tecnológica latino-americana, estudos sociais da ciência \& tecnologia, história da tecnologia e relação universidade-movimentos sociais. Foi coordenador (2008-2010) e sempre foi professor do Curso de Especialização - Economia Solidária e Tecnologia Social na América Latina (Unicamp), Professor do Curso de Extensão -Estado e Políticas Públicas (Unicamp), Professor e apoiador do curso - Gestão Estratégica Pública- -Unicamp (Turma Rio Claro-SP, 2010). É pesquisador do Projeto - Tecnologia Social (IDRCCanadá/Unicamp e Universidade Nacional de Quilmes-Argentina). Professor do curso de especialização semi-presencial de Gestão Pública e Sociedade (parceria UFT-Gapi Unicamp). Professor do curso de Especialização de Gestão Educacional da Faculdade de Educação - Unicamp, de 2005 a 2006. Membro dos grupos de Pesquisa Instituto Brasileiro de Estudos Contemporâneos (IBEC-São Paulo), Grupo de Análise de Política de Inovação (GAPI-Unicamp) e Organizações e Democracia (Unesp-Marília). É Docente da Faculdade de Filosofia e Ciências da Unesp Marília, desde fev. de 2011. ORCID: http://orcid.org/0000-0001-5247-3684 Email: hetanov@yahoo.com.br

2 Ver - por exemplo - Sader (1988) e Dal Ri e Vieitez (2008).

3 Para isso, ver também Netto (2010), Sampaio Jr. (2013), Minto (2015) e Deo (2014).

${ }^{4}$ As marcas da nossa matriz colonial baseada no latifúndio, na produção voltada para o exterior e no trabalho escravo estão gravadas no país até hoje. Para esse debate, ver Prado Jr. (2002), Sampaio Jr. (2013), Ziegler (2012), Macedo (2015), MST (2014) e Deo (2017).

5 Ver o interessante artigo de Walter Porto Gonçalves et al. (2016).

${ }^{6} \mathrm{Na}$ América Latina como um todo, eclodiram inúmeras lutas por terra, por habitação, por água, por saneamento básico, por saúde, por educação, por controle dos recursos naturais, entre outras. Em geral, essas lutas "estacionaram" em demandas pontuais, especialmente porque a ofensiva do capital não permitiu aos trabalhadores sua ultrapassagem, ao contrário, tendeu a jogar os trabalhadores como um todo na miséria ou na defensiva. Mas também é preciso destacar que nos falta uma teoria adequada para a transição ao comunismo na região.

${ }^{7}$ Segundo relatório da Comissão Pastoral da Terra (CPT, 2017), de 2010 a 2016, o avanço do agronegócio fez dobrar o número de assassinatos no campo. Saltamos de cerca de 30 para 61. Se incluirmos as tentativas de assassinato, os números são estarrecedores. Isso para não falar do trabalho análogo ao escravo em pleno século XXI. 